Supplement of Biogeosciences, 15, 5271-5286, 2018

https://doi.org/10.5194/bg-15-5271-2018-supplement

(C) Author(s) 2018. This work is distributed under

the Creative Commons Attribution 4.0 License.

(c) (1)

Supplement of

\title{
Aluminium in the North Atlantic Ocean and the Labrador Sea (GEOTRACES GA01 section): roles of continental inputs and biogenic particle removal
}

Jan-Lukas Menzel Barraqueta et al.

Correspondence to: Jan-Lukas Menzel Barraqueta (jmenzel@geomar.de)

The copyright of individual parts of the supplement might differ from the CC BY 4.0 License. 


\section{Supplementary information}

Table S1: Concentrations of total dissolvable Al (TdAl) in iceberg (ice) and fjord samples in Godthåbsfjord (SW Greenland). Iceberg samples are in the $\mathrm{nM}$ range and fjord samples are in the $\mu \mathrm{M}$ range. Ice samples were collected at

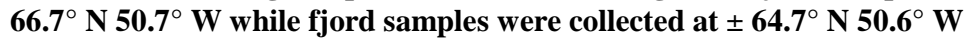

\begin{tabular}{|l|l|}
\hline Samples & {$[\mathrm{TdA}]$} \\
Ice 1 & 65.91 \\
Ice 2 & 35.65 \\
Ice 3 & 29.92 \\
Ice 4 & 29.31 \\
Ice 5 & 59.31 \\
Ice 6 & 62.89 \\
Ice 7 & 52.48 \\
Ice 8 & 112.85 \\
Ice 9 & 52.50 \\
Ice 10 & 45.56 \\
Ice 11 & 60.59 \\
Fjord 1 & 4.09 \\
Fjord 2 & 7.46 \\
Fjord 3 & 17.73 \\
Fjord 4 & 20.10 \\
\hline Fjord 5 & 14.65 \\
\hline
\end{tabular}




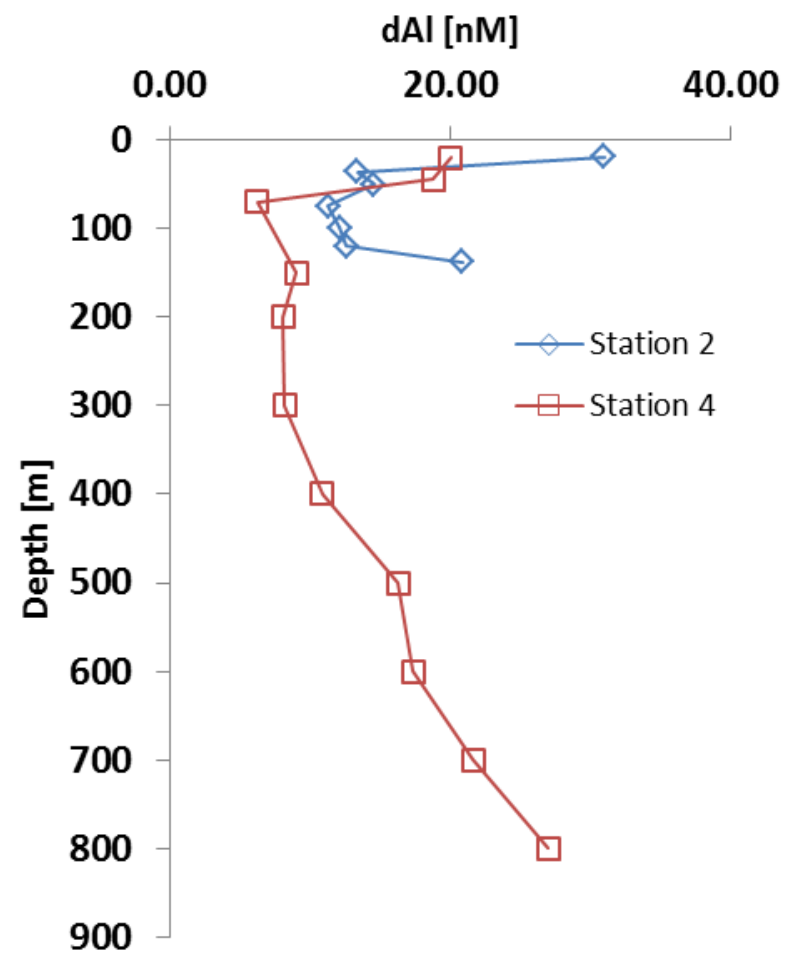

Figure S1: Deep profiles for dAl over the Iberian shelf.

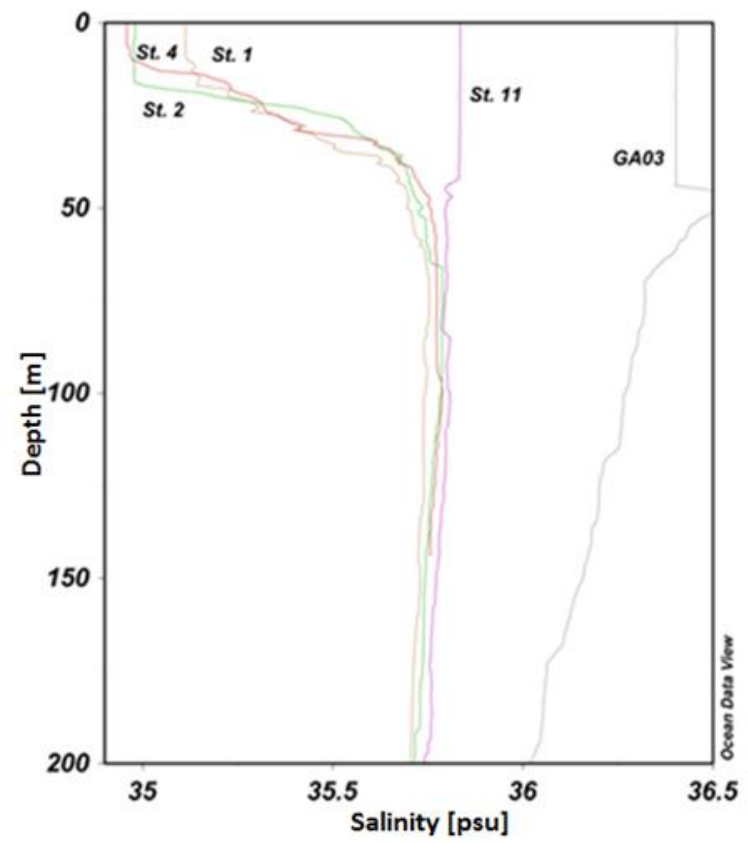

Figure S2: Salinity profiles showing an influence of fresh water for stations 1, 2 and 4. Profile labelled GA03 (Measures et al., 2015) shows the salinity profile for the closest station to the Tagus estuary (For reference on the location of the profile labelled GA03 please refer to Fig. 3). Plot created in Ocean Data View (Schlitzer, 2017). 


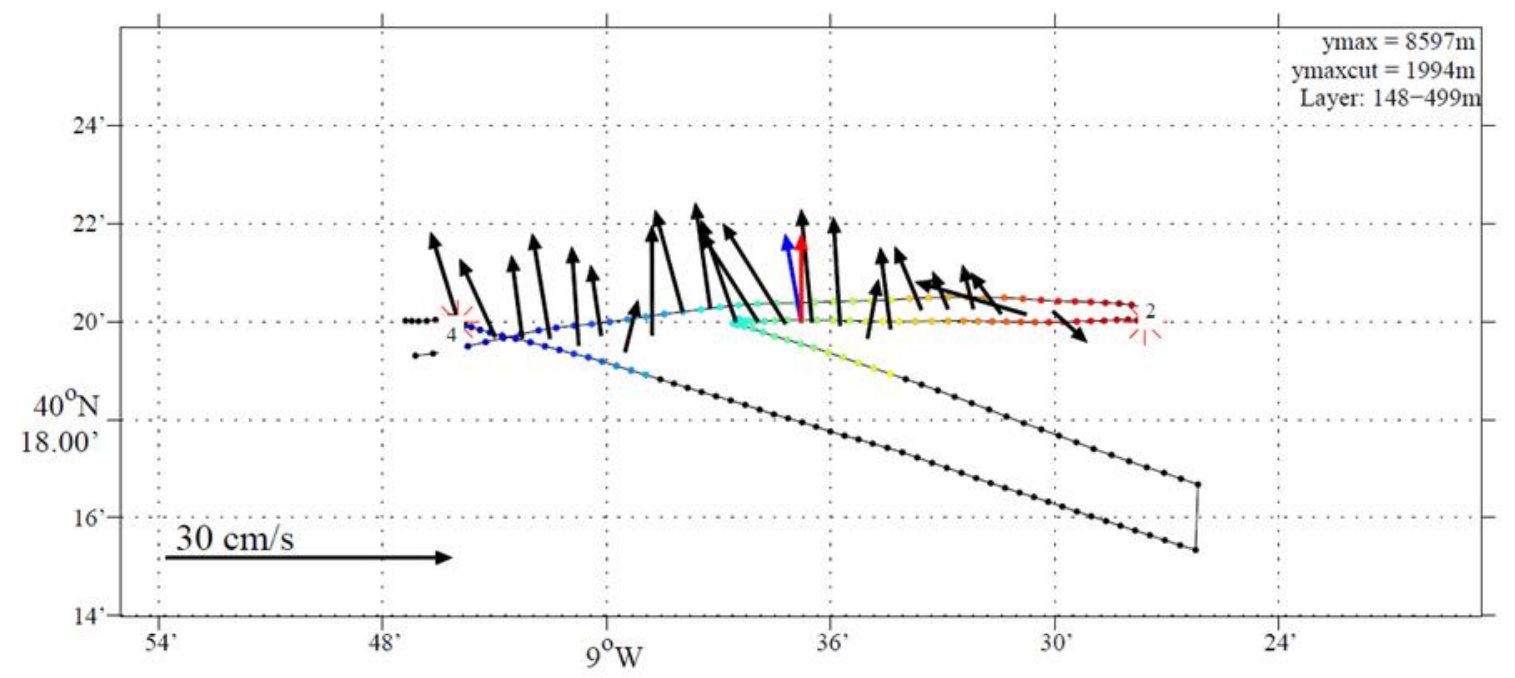

Figure S3: ADCP data between stations 4 and 2 during the GEOVIDE transect. The ADCP data showed a northward direction of the surface currents.

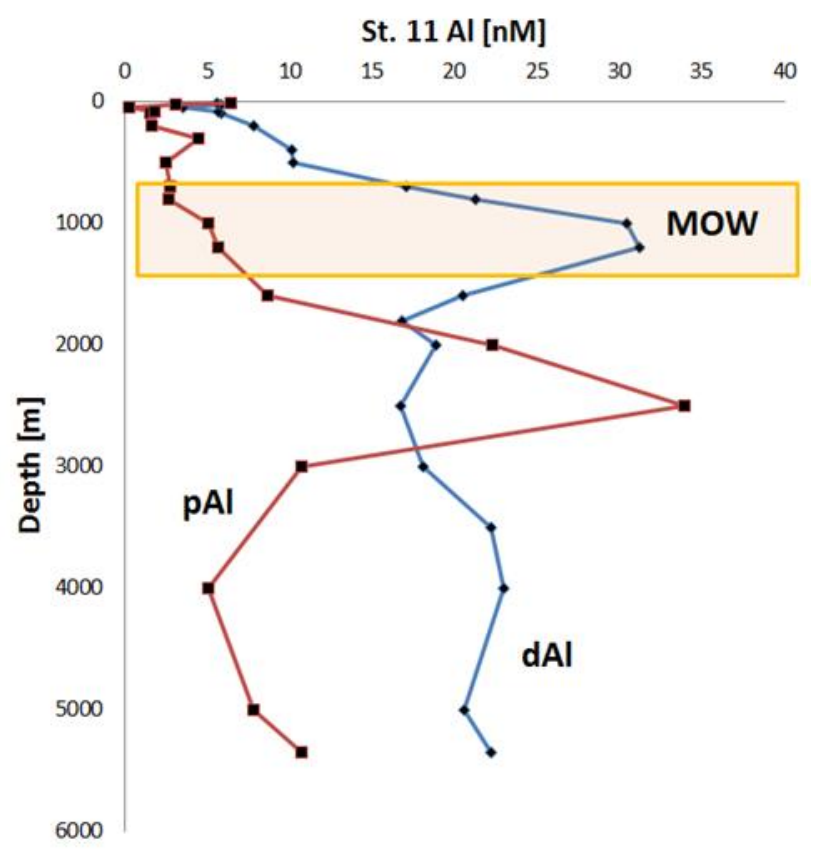

Figure S4: Profiles of dissolved and particulate $\mathrm{Al}[\mathrm{nM}]$ at station 11. The orange box represents the approximate depth of the Mediterranean Overflow Water (MOW). The high particulate Al observed at ca. $2500 \mathrm{~m}$ depth is associated with inputs from the Iberian margin. 


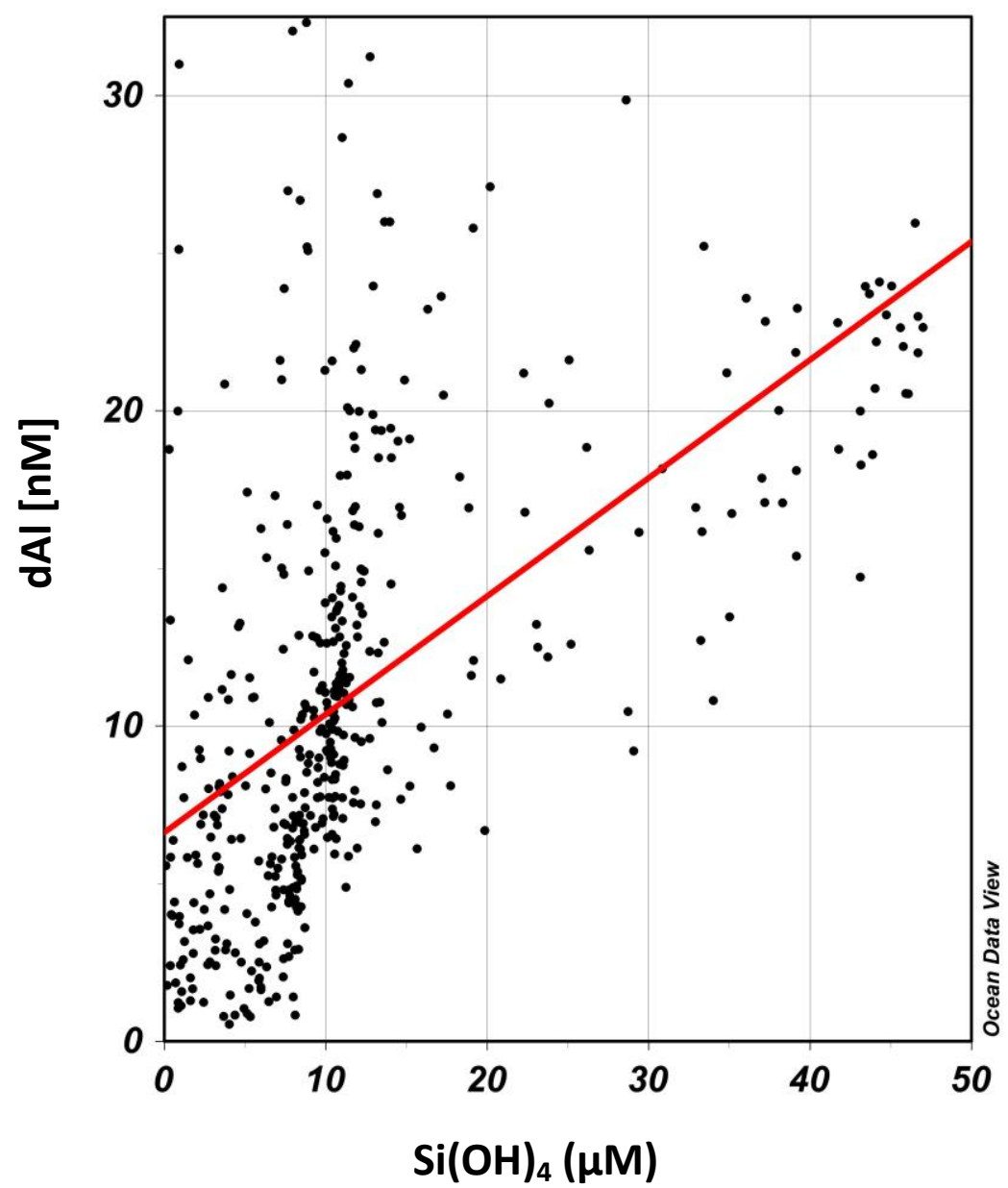

Figure S5. Dissolved Al versus silicate for the GEOVIDE cruise. 


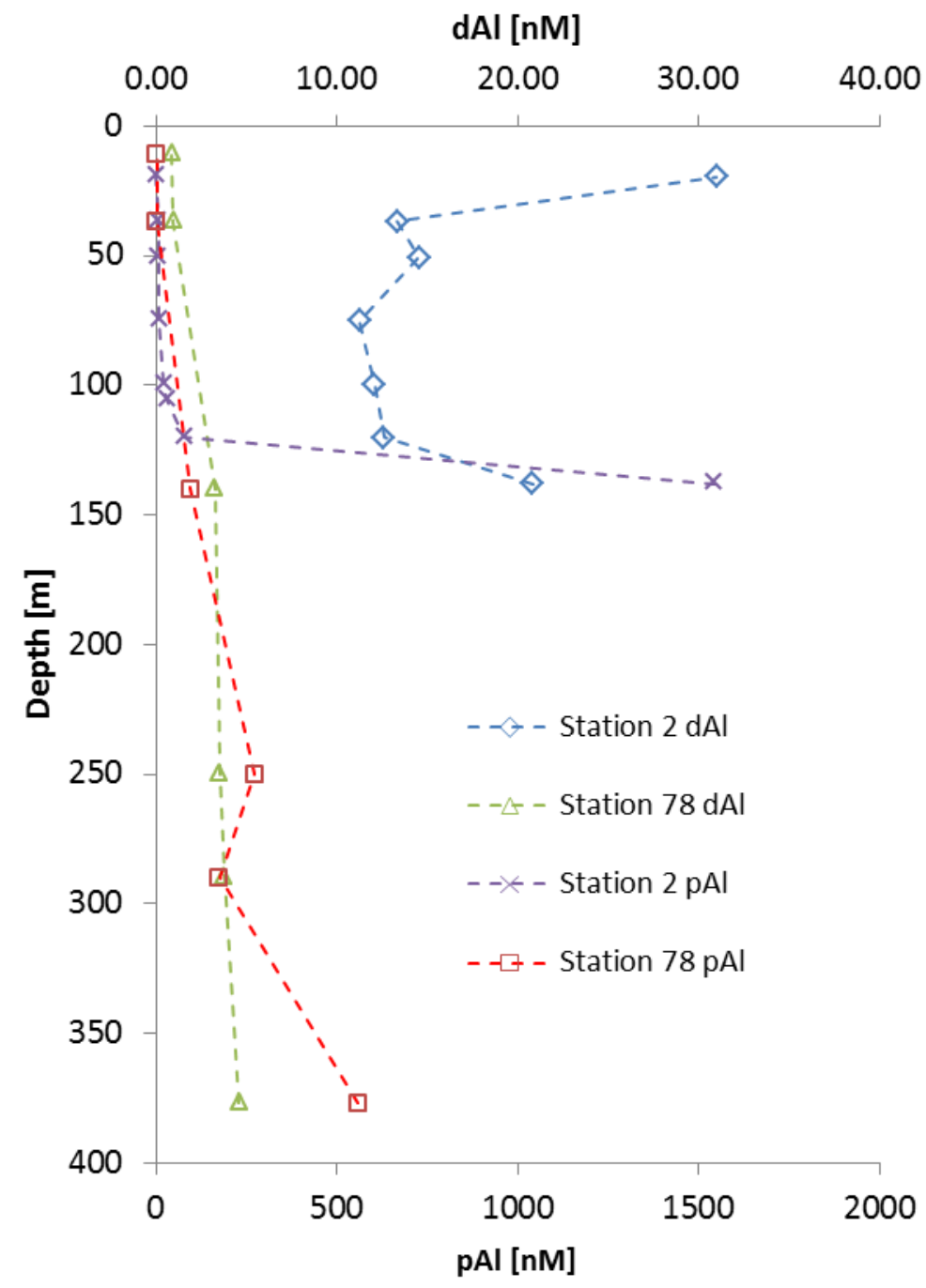

Figure S6. Profiles for dAl and pAl (Gourai et al., special issue) for the Iberian (Station 2) and the Newfoundland shelves (Station 78). 


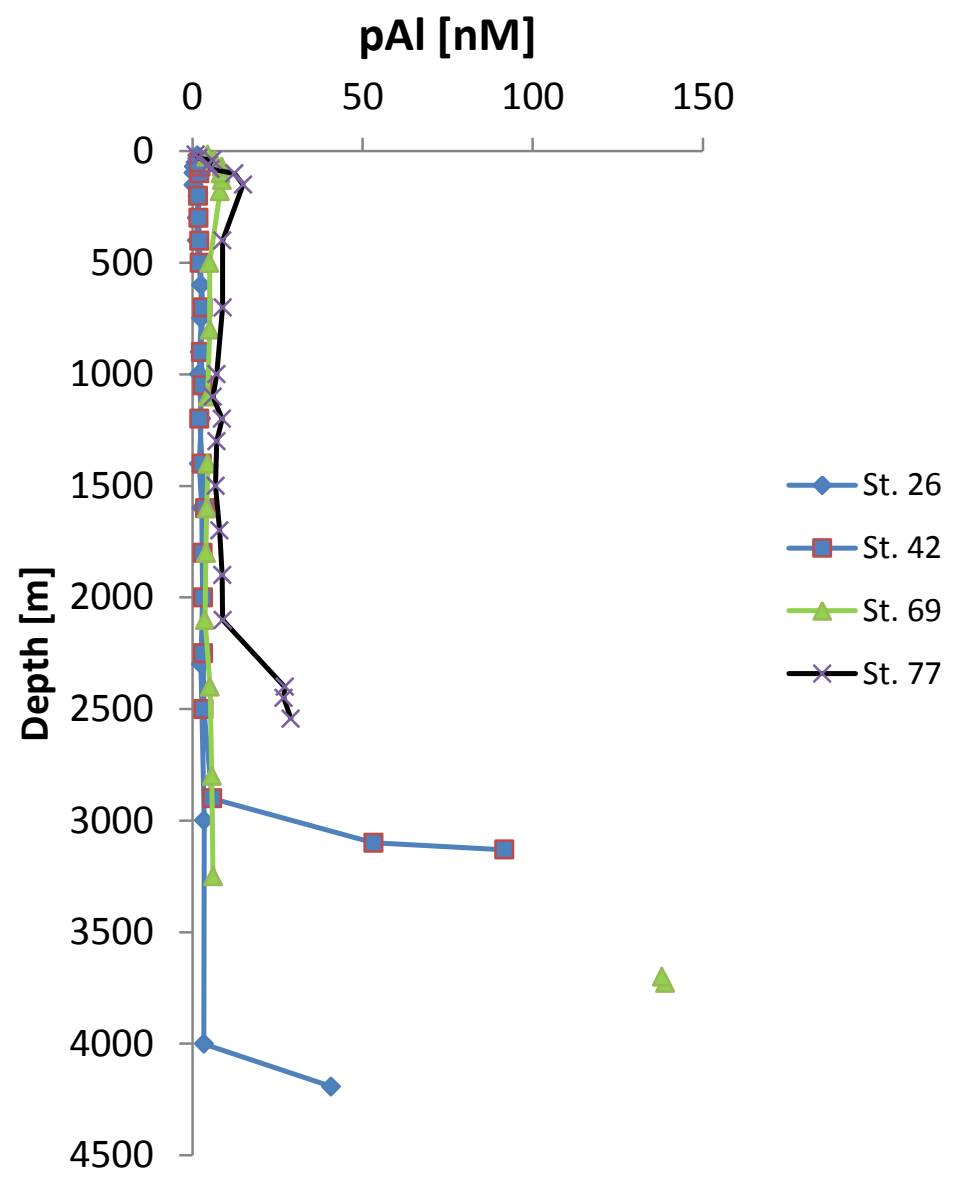

Figure S7: Profiles for pAl for different stations along the cruise. 